\title{
«LAS LEYES DEL HONOR» \\ HONOR Y ESTRATIFICACIÓN SOCIAL EN EL DISTRITO DE LA AUDIENCIA DE QUITO (SIGLO XVIII)
}

\author{
POR
}

\author{
CHRISTIAN BÜSCHGES
}

Universidad de Colonia, Alemania ${ }^{1}$

\begin{abstract}
El presente estudio examina la naturaleza y la función del concepto del «honor» en el distrito de la Audiencia de Quito durante el siglo XVIII, analizando una amplia gama de documentos, en su mayoría de origen judicial. El honor se presenta en su esencia como un concepto de distinción y exclusión social, empleado por las capas altas de las sociedades locales, reflejando identidades sociales que van más allá de características puramente económicas y muestran de esta manera rasgos típicos de una sociedad del antiguo Régimen.
\end{abstract}

En el año 1781, el hacendado quiteño Ignacio Cevallos y Tena dirigió una carta al Consejo de Indias en la que, «deseoso de conservar el honor de su familia», se quejó de la decisión del tribunal de la $\mathrm{Au}-$ diencia de Quito de declarar injusta su disconformidad contra - según él- el «matrimonio desigual» que su hijo Antonio, de 22 años, quería contraer con Vicenta Ontañeda, de 35 años y «de clase mestiza». Cevallos basó su oposición contra tal matrimonio en el «muy ínfimo nacimiento» de la madre de Vicenta, esposa de Juan de Ontañeda, un primo hermano suyo que había «cometido el error de casarse con una criada suya de nacimiento oscuro y abatido». Por consiguiente, debería seguirse la Real Pragmática de matrimonios de 1776, que au-

1 Una gran parte de la presente investigación fue facilitado por una beca de la Deutsche Forschungsgemeinschaft que me hizo posible un viaje a los archivos quiteños en julio y agosto de 1995. Un primer esbozo de la temática fue presentado en el 11. Congreso Internacional de la Asociación de Historiadores Latinoamericanistas Europeos, en Liverpool, 17.-22. septiembre de 1996. Doy mis agradecimientos a María Rosa Fernández Cuesta para su revisión de mi traducción del original alemán del presente artículo al español. 
torizaba a los padres a denegar el consentimiento al matrimonio de sus hijos menores en caso de una desigualdad social del cónyuge elegido. En contra de la baja posición social de la madre de Vicenta, Cevallos alegó «la posesión de nobleza que por sí, por su mujer [Josefa Donoso] y toda la familia gozaba, como descendiente de los primeros conquistadores y pobladores del Reino».

Los padres de Vicenta, en cambio, habían iniciado el pleito porque su hija había quedado encinta, hecho que les llevó a insistir en la realización del matrimonio, fundándose en el —según Cevallos«común pretexto de reparar el honor» de la hija, defendiendo al mismo tiempo su elevado rango social.

En el juicio de primera instancia el corregidor de Quito asintió con la oposición de Cevallos, pero más adelante, la Audiencia revocó el dictamen y asignó a la pareja la facultad de acudir al obispo para «usar de su derecho como les conviene». La Audiencia basó su dictamen en el hecho de que el embarazo de Vicenta había precedido a la promulgación de la mencionada Pragmática, aunque también hizo constar que consideraba la relación social entre las dos partes «virtualmente desigual».

Ante la nueva situación, Cevallos cambió su estrategia. Ahora destacaba la necesidad de una dispensa matrimonial, dadas las relaciones de parentesco que existían entre él y su primo hermano Juan de Ontañeda. El obispo de Quito, que entretanto se había hecho cargo del asunto, trató de «impugnar la concesión de la dispensa» fundándose en la Pragmática Real y en «el derecho natural, Divino y positivo» según los cuales, la Iglesia siempre se había opuesto a los matrimonios que no acataban la autoridad paterna y disturbaban la paz familiar, incluso si el cónyuge elegido fuese una «persona honesta».

Sin embargo, llegado el momento de la revisión del pleito por el Consejo de Indias, éste, después de revisar los documentos entregados por Cevallos, siguió el dictamen de su fiscal de denegar la petición y remitió la decisión del pleito al obispo de Quito. Según la Cámara de Indias, lo que importaba para la aplicación de la Pragmática no era la fecha del embarazo de Vicenta, sino la del matrimonio pretendido. Con este dictamen quedó sin efecto también la solicitud 
de Cevallos de poder enviar a su desobeciente hijo a Cartagena, donde «cumplirá mejor con las leyes del honor» ${ }^{2}$

La noción del «honor», al que se alude en diversas ocasiones en el pleito referido, fue en la época moderna, y aún en la contemporánea, un fenómeno de gran trascendencia social, cuyo significado y cuyas funciones varían según los diferentes contextos históricos, culturales y sociales. Resulta sumamente difícil encontrar una definición del término y un concepto general o central del honor, válido para todas las sociedades, épocas y grupos sociales, incluso si sólo se considera el «mundo occidental» y además, tal definición general correría el peligro de perder todo su valor analítico. No obstante, debe constatarse que la idea del honor facilitó -y aparentemente en algunas regiones y sociedades todavía guía de manera decisiva - los modelos y reglas fijas de comportamiento tanto en las relaciones personales (o individuales) como en las sociales. En esta ponencia me limito a presentar algunas reflexiones sobre cómo deben entenderse estas «leyes del honor» y su trascendencia y funciones sociales en el distrito de la Audiencia de Quito durante el siglo XVIII.

\section{CONSIDERACIONES TEÓRICAS}

Una clasificación teórico-metodológica del fenómeno del honor en el período colonial debe tener en cuenta dos grandes corrientes de la investigación internacional. Se puede distinguir un enfoque antropológico, cuyo objeto de estudio son las culturas y pueblos contemporáneos localizados en la región mediterránea, sobre todo de la esfera cristiana-occidental, y cuya metodología se basa principalmente en trabajos de campo. Las investigaciones acerca del así llamado «complejo mediterráneo del honor» son especialmente difundidas en la investigación anglosajona siguiendo la tradición de los pioneros en este campo, Peristiany y Pitt-Rivers ${ }^{3}$. La segunda corriente pre-

2 AGI, Quito, leg. 314. El matrimonio se efectuó cuatro años más tarde, Jorge Moreno Egas, "Resumen alfabético del segundo libro de matrimonios de españoles de la parroquia de El Sagrario de Quito, 1764-1805", Revista del Centro Nacional de Investigaciones Genealógicas y Antropológicas. Quito, vol. 3, 1981, pág. 222.

3 Véase sobre todo John G. Peristiany (ed.), El concepto del honor en la sociedad mediterránea, Barcelona, Editorial Labor, 1968 (original inglés 1966; Julian PITT-RIVERS, "Honor", International Encyclopedia of the Social Sciences. vol. 6, New York, 1968, págs. 
senta un enfoque sociológico-histórico, cuya metodología se centra en la interpretación de textos literarios, jurídicos y moralistas y en el análisis de actas judiciales, sobre todo de autos matrimoniales.

\section{a) El enfoque sociológico-histórico}

Este enfoque parte de la conocida distinción tipológica de Max Weber entre la «situación estamental» y la «situación de clase». Según Weber, el honor ocupa un lugar estratégico en las sociedades de la época moderna en cuanto que es considerado como la esencia, o sea, el concepto central y factor decisivo, de la diferenciación social en la así llamada «estructura estamental» de la sociedad. La naturaleza del concepto del honor en esta estructura estamental es según Weber:

\footnotetext{
«En oposición a la "situación de clase" condicionada por motivos puramente económicos, llamaremos "situación estamental" a todo componente típico del destino vital humano condicionado por una estimación social específica - positiva o negativa - del "honor" adscrito a alguna calidad común a muchas personas» ${ }^{4}$.
}

Este concepto del honor, típico de las sociedades del Antiguo Régimen, no se basa por tanto esencialmente en la fama que se reconocía a una persona como individuo y por una calidad personal, sino que el honor correspondía a una persona en primer lugar como miembro de un cierto grupo social, o sea, un estamento. El honor es en este sentido un «honor estamental» (Standesehre). Repecto a la esencia de esta definición formal o funcional del concepto del honor como expresión de la evaluación social específica de cada grupo social o estamento Weber dice:

503-510; PERISTIANY y PITT-RIVERS (eds.), Honor and Grace in Anthropology. Cambridge, 1992.

4 WeBER, Max, Economía y Sociedad. Esbozo de sociología comprensiva, edición preparada por Johannes Winckelmann, nota preliminar de José Medina Echavarría, México, Fondo de Cultura Económica, 4a ed., 1979, pág. 687; véase también ibidem, págs. 242246 y págs. 316-322; cf. Roland MOUSNIER, Les hiérarchies sociales de 1450 à nos jours. Paris, Presses Universitaires de France, 1969.

R. I., 1997, n. $^{\circ} 209$ 


\begin{abstract}
«En cuanto a su contenido, el honor correspondiente al estamento encuentra normalmente su expresión ante todo en la exigencia de un $\mathrm{mo}^{-}$ do de vida determinado a todo el que quiera pertenecer a su círculo» ${ }^{5}$.
\end{abstract}

Los diferentes grupos sociales o estamentos que se formaron en Europa a partir de la Edad Media en torno a un prestigio de descendencia o profesión propia (por ejemplo clero, nobleza, burguesía, artesanos) se distinguían entre sí por un honor particular que se expresó en un modo de vivir o «código de honor» específico y convencional, coadyuvado por privilegios y deberes propios. El honor de los diferentes estamentos se distinguía entre otros factores por la restricción de las relaciones sociales y especialmente del connubio en el círculo del propio grupo social, como también por una indumentaria o profesiones específicas.

De esta manera se desarolló un orden social de estamentos que se diferenciaban por el grado y la calidad del honor, cuya manifestación más elaborada se atribuyó al honor de la nobleza como capa social más alta y «estamento de honor» (Ehrenstand) propio. La posición elevada y el honor particular de la nobleza se expresó tanto en un especial prestigio hereditario, como en privilegios, deberes o también corporaciones propios. En el modo de vivir típico de la nobleza se destacaban hábitos propios de consumo, así como también el intento de una apropriación exclusiva de algunas profesiones y actividades económicas (como la tenencia de la tierra) y la discriminación social de otras actividades como el trabajo dependiente o mecánico (artesanal) ${ }^{6}$.

La insistencia en un honor específico y la elaboración de códigos de honor propios de los diferentes estamentos sirvió tanto para la integración de los diferentes grupos sociales como para la estabilización y justificación de un orden social orgánico-jerárquico y la distinción y exclusividad de la nobleza como grupo social más alto y beneficiario especial de este orden social ${ }^{7}$.

\footnotetext{
5 WEBER, ibidem, pág. 688.

Ibidem, pág. 246.

7 Véase sobre el concepto del honor, entendido como un rasgo fundamental de la sociedad estamental, y la posición particular de la nobleza dentro de este tipo de sociedad: Friedrich ZUNKEL, "Ehre, Reputation", en: Otto BRUNNER entre otros (ed.), Geschichtliche Grundbegriffe. Historisches Lexikon zur politisch-sozialen Sprache in Deutschland. vol. 2, Stuttgart, Ernst Klett Verlag, 1975, págs. 1-63.
} 
La evaluación social (positiva o negativa) en bloque (y a priori) de diferentes grupos sociales y su más o menos estricta regulación por leyes, tradiciones y convenciones tuvo la función de eliminar o restringir al máximo la regulación libre por el mercado, siendo éste el mecanismo clave que organiza las relaciones y la jerarquía social en la «sociedad de clases». Según Weber la «posición de clase» resulta:

«dentro de un determinado orden ecónomico, de la magnitud y naturaleza del poder de disposición (o de la carencia de él) sobre bienes y servicios y de las maneras de su aplicabilidad para la obtención de rentas o ingresos». 8 .

No es pues de extrañar que en la semántica del honor estamental, tal como se manifiesta en la documentación de la época moderna, falta cualquier alusión al rendimiento o a la riqueza como un valor en si $^{9}$.

Debe entenderse que Weber concepcionó los términos «situación estamental» $\mathrm{y}$ «de clase» como dos «tipos ideales» (Idealtypen) de la diferenciación social, o sea como categorías que ni corresponden necesariamente a dos tipos de sociedades netamente opuestas ni abarcan siempre y exclusivamente todas esferas de una sociedad. De esta manera, las expresiones «sociedad de estamentos» o «de clase» deben emplearse según la trascendencia decisiva que una de las dos «situaciones» tiene frente a la otra para la diferenciación y jerarquía social dentro de una sociedad específica.

De todos modos, de la concepción weberiana se deduce $-\mathrm{y}$ se confirma en las trasformaciones políticas, económicas y culturales que experimentaron las sociedades europeas durante los siglos XVIII y XIX - que en la medida en que los mecanismos del mercado (o de los mercados) se impusieron en la estructura de las relaciones sociales, se redujeron los privilegios hasta la desaparición de los grupos estamentales, a la vez que los aspectos del honor estamental, vincu-

\footnotetext{
8 WeBER [4], pág. 242.

9 Respecto a la relación entre estructura estamental y economía del mercado, y entre nobleza y actividades económicas cf. Barbara STOLLBERG-RILINGER, "Handelsgeist und Adelsethos. Zur Diskussion um das Handelsverbot für den deutschen Adel vom 16. bis zum 18. Jahrhundert". Zeitschrift für Historische Forschung, vol. 15, 1988, págs. 273-309; Pere MolAS, La burguesía mercantil en la España del Antiguo Régimen, Barcelona, Cátedra, 1985.
}

R. I., $1997, \mathrm{n}^{\circ} 209$ 
lados tradicionalmente a la estratificación social, perdieron su significado original.

Sin embargo, en cuanto al contenido del concepto del honor éste se remontaba en parte a tradiciones más remotas e incluía nociones diferentes o, incluso, contrarias a la dimensión estamental. Ya desde la misma Edad Media, en los escritos de teólogos, juristas y moralistas se observan reflexiones que daban una trascendencia alternativa a la corriente principal y determinante que vinculaba la idea del honor directamente a la estratificación social. Esta crítica primordialmente ética del honor estamental tiene sus raíces sobre todo en la tradición cristiana. En este contexto, el honor de una persona se consideraba en primer lugar como un valor interior y universal de todos los seres humanos, en tanto que creaturas según la imagen de Dios. Además, no sólo se consideraba el honor en su esencia y en su más alta expresión como una virtud en el sentido moral, sino también en el sentido de ánimo (coraje) y valentía (bravura $)^{10}$. De acuerdo con esta tradición, durante toda la época moderna se siguió considerando el honor tanto como un valor individual, como universal, si bien esta idea no tuvo una trascendencia social decisiva hasta la época de la Ilustración, en el siglo XVIII ${ }^{11}$. Por el contrario, con la formación de la sociedad estamental y al iniciarse el desarrollo del Estado moderno en el transcurso de los siglos XVI y XVII, se impuso la referida jerarquía social, con sus rígidas escalas del honor, como una importante fuente de oficios y funciones de honor, a cuya estabilidad contribuía el monarca absoluto. En este contexto, el honor se transformó en un concepto e instrumento de legitimación y defensa de la supremacia social de la nobleza.

Justamente esa insistencia y exageración del honor como un concepto estamental y su nivelación y reducción a una reputación particular reclamada por parte de la nobleza fue el punto clave de la críti-

10 La idea del honor como virtud, en su doble dimensión de ética cristiana y de valentía (varonil), puede observarse en su más temprana y decisiva expresión social en la caballería medieval; véase Günter EIFLER (ed.), Ritterliches Tugendsystem. Darmstadt, Wissenschaftliche Buchgesellschaft, 1970.

11 Véase para el caso español Antonio Domínguez ORTIZ, Las clases privilegiadas en el Antiguo Régimen. Madrid, Ediciones Istmo, 3a ed., 1985; Claude CHAUCHADIS, Honneur, morale et société dans l'Espagne de Philippe II, Paris, Editions du CNRS, 1984; Antonio Maravall, Poder, honor y élites en el siglo XVII, Madrid, Siglo XXI Ediciones, 3a ed., 1989; idem, "La función del honor en la sociedad tradicional". Ideologies and Literature, vol. 2, n. $^{\circ} 7,1978$, págs. 9-27. 
ca del siglo XVIII. A lo largo del siglo, esa crítica pasó de un discurso tradicional sobre la reivindicación de una «nobleza de virtud» opuesto a la «nobleza de sangre», a una crítica radical que contraponía a la noción del honor social o estamental la idea de un honor interior y universal que tuvo su raíz en el racionalismo de la primera fase del movimiento de la Ilustración. Según Zunkel:

«este término general del honor, sin límites legales, vino a ser la posición ideológica de la crítica del "hombre razonable" de un orden social y de honor basado en el nacimiento y en privilegios [...]. De esta manera, el honor se libró de la evaluación por los demás y fue sometido solamente al juicio moral personal de las acciones propias» ${ }^{12}$.

Esta trasformación del concepto del honor hacia una integridad personal y, a la vez, una dignidad humana, y la desvinculación del honor de la estratificación social y de los grupos sociales particulares tuvo como resultado obvio la pérdida de su poder normativo y trascendencia social aunque se conservó, en parte hasta hoy en día, en ciertos sectores e instituciones sociales (por ejemplo entre los médicos) $y_{2}$ en un sentido menos estricto y explícito, como reputación o, utilizando una expresión más contemporánea, como prestigio social.

\section{b) El enfoque antropológico}

La mencionada persistencia de un importante significado social del concepto de honor se verifica sobre todo en los estudios antropológicos sobre algunas regiones del sur de Europa, o sea en el área mediterráneo ${ }^{13}$. Con el trasfondo de la tipología de Weber este hecho se explicaría básicamente por las características tradicionales de estas regiones, que frente a la modernización económica, política y cultural en las regiones del centro y norte europeo a partir del siglo XVIII, conservaron sus rasgos sociales tradicionales. Por otra parte, los antropólogos que han investigado estas «sociedades tradiciona-

\footnotetext{
12 Zunkel [7], págs. 25 y 26.

13 Véase i.e. la literatura indicada en [3]. Sobre la trascendencia del honor en las sociedades de la parte árabe de la región mediterránea véase también Frank H. STEWART, Honor. Chicago, The University of Chicago Press, 1994.
} 
les» destacan también aspectos del fenómeno del honor en estas regiones, entendidos como diferentes del carácter primordialmente estamental del honor al que se ha aludido anteriormente. En la investigación antropológica sobre el fenómeno del honor se destacan como contenido y rasgos más característicos: su función de valoración propia y de otras personas, la diferenciación entre el «honor interior» (moral) y «exterior» (social), la importancia de la familia y de la descendencia para la reputación, y la distinción entre el honor masculino (coraje) y el femenino (especialmente el comportamiento sexual). Al mismo tiempo, no aparece generalmente mención alguna sobre la dimensión estamental del honor en el sentido de la tipología de Weber ${ }^{14}$.

En contra de algunas críticas del así llamado «complejo mediterráneo del honor» hay que resaltar, sin embargo, que también este complejo incluye una evidente dimensión «vertical» o estratificadora del honor en cuanto a ser éste también un instrumento en la lucha por el control de los escasos recursos económicos ${ }^{15}$. En tal sentido, Arnold Zingerle habla solamente de un cierto «desnivel europeo» entre Europa septentrional y central y las «regiones marginales de la sociedad moderna» en el área mediterránea respecto al desarrollo de «estructuras estamentales como base de una mentalidad del honor típica», frente al predominio de patrones más bien personales o familiares de la concepción del honor ${ }^{16}$. De todos modos, cabe destacar que las investigaciones históricas sobre las regiones del sur europeo revelan también la existencia de una fuerte noción estamental del

14 Arnold ZingerLE, "Ehre in Geschichte, Kultur und Gesellschaft. Eine Einleitung", en: Friedhelm GuTTANDIN (ed.), Soziologie der Ehre. Hagen, Fernuniversität Hagen, Kurseinheit 2, 1989, pág. 120.

15 Respecto a la crítica de los trabajos sobre el "complejo mediterráneo del honor" veáse Christian GioRDANO, "Der Ehrkomplex im Mittelmeerraum: sozialanthropologische Konstruktion oder Grundstruktur mediterraner Lebensformen?", en: Ludgera VoGT y Arnold Zingerle (ed.), Ehre. Archaische Momente in der Moderne. Frankfurt/M., Suhrkamp, 1994, págs. 173-179; H. DRIESSEN, "Anthropologists in Andalusia: The Use of Comparison in History", Man. vol. 16, 1981, págs. 451-462.

16 Véase GioRDANo [15], págs. 172-192. También STEWART [13] destaca los rasgos comunes entre el concepto mediterráneo occidental y otros conceptos del honor en el "hemisferio cristiano" frente a un ideario del honor muy diferente en el mundo islámico o árabe.

R. I., $1997, \mathrm{n}^{\circ} 209$ 
honor ${ }^{17}$. Por consiguiente, parece razonable, como propone Christian Giordano, no exagerar las diferencias entre ambos enfoques y admitir en ambos casos una cierta diversidad histórica y regional respecto a las características dominantes del concepto del honor.

\section{EL CONCEPTO DEL HONOR EN LA AMÉRICA ESPAÑOLA DURANTE EL PERÍODO COLONIAL}

Hasta ahora todavía no existe una investigación profunda sobre el desarrollo, el contenido y la función social del concepto del honor en la América Española. Además, a excepción de los estudios, indudablemente importantes, elaborados por y en el entorno de PittRivers y Peristiany, la investigación internacional - sobre todo los estudios empírico-históricos sobre el concepto del honor en la época moderna - todavía no ha incidido de manera satisfactoria en la discusión sobre el tema en el Nuevo Mundo.

Entre los pocos estudios que tratan Hispanoamérica se encuentra el artículo de Ann Twinam sobre la relación entre honor (primordialmente femenino), sexualidad e ilegitimidad en la América Española durante toda la época colonial ${ }^{18}$. La base documental de este estudio la forman solicitudes de legitimación presentadas al Consejo de Indias entre 1630 y 1820 , pero que en su mayoría datan de un período que va desde 1780 hasta 1809. El análisis de estos documentos ha proporcionado unos resultados que se asemejan considerablemente a la investigación antropológica e histórica sobre distintas regiones europeas: Así, se puede observar una noción particular acerca del honor femenino como un fenómeno que regulaba en primer lugar el comportamiento sexual, es decir, que tenía la función de impedir y condenar las relaciones sexuales pre- y extramatrimoniales de la mujer. Junto a la influencia de la imagen de la mujer como virgen, tal como fue presentada por la religión cristiana y propagada por la Iglesia católica, esta idea sobre el comportamiento ideal y, por con-

\footnotetext{
17 Véase para España Julio CARo BAROJA, "Honor y vergüenza. Examen histórico de varios conflictos", en: [3], págs. 77-126; cf. además los estudios históricos de CHAUCHADIS y MaraVAll [11].

18 Twinam, "Honor, Sexuality, and Illegitimacy in Colonial Spanish America", en: Asunción LAVRIN (ed.), Sexuality and Marriage in Colonial Spanish America. Lincoln y Londres, University of Nebraska Press, 1989, págs. 118-152.
} 
siguiente, del honor particular de la mujer tuvo también una importante dimensión social. El control de la sexualidad femenina se debe entender como un factor importante en el mantenimiento del honor de la familia entera, en cuanto que la mencionada exigencia de limitar las relaciones sociales a la misma capa social tuvo su dimensión más importante en el connubio. Además, como en el caso de los «matrimonios desiguales», la mácula de la ilegitimidad no sólo implicaba la pérdida de la reputación de la respectiva persona y de su familia y descendientes, sino que - como también se expresaba en una legislación explícita - impedía o reducía igualmente de manera considerable la posibilidad de ejercer funciones y cargos importantes en la sociedad. En síntesis, tal como parece en el análisis de Twinam, el concepto del honor se caracterizó durante el período colonial por los siguientes rasgos generales: $\mathrm{El}$ honor de una persona derivaba tanto de la ascendencia como del comportamiento individual de una persona. La autora destaca la conexión entre el concepto del honor y la definición y defensa de la posición social dentro de un orden social jerárquico, sin embargo, no precisa las características específicas tanto del concepto del honor como del supuesto orden social. El concepto de honor que Twinam presenta fue en primer lugar definido y defendido por la capa social alta para mantener su elevada posición social. Dada la base documental y la limitación a las solicitudes de legitimación y al honor feminino, el artículo de Twinam no logra sino exponer algunas ideas generales sobre el contenido y la función social de la noción del honor durante la época colonial respecto a un estrato social.

De mayor interés y planteamiento más específico sobre la trascendencia del concepto del honor en la América Española es el libro de Patricia Seed que trata, en un enfoque más amplio, el fenómeno del honor en el virreinato de Nueva España ${ }^{19}$. El estudio de Seed se basa primordialmente en la documentación de los autos matrimoniales presentados ante la corte eclesiástica o el tribunal de la Audiencia durante toda la época colonial. Al analizar cómo se administraba la justicia respecto a la verificación o el impedimento de los matrimonios respectivos, Seed destaca dos etapas, durante las cuales se observa la vigencia de conceptos del honor totalmente diferentes en los

19 SEED, To Love, Honor, and Obey in Colonial Mexico. Conflicts over Marriage Choice, 1574-1821. Stanford, Stanford University Press, 1988. 
procesos. En la primera época, durante los siglos XVI y XVII, el honor se entendía como un valor individual, o sea como «virtud». En la segunda etapa, que - después de un período de transición que va aproximadamente de 1670 hasta 1730 - abarca todo el siglo XVIII hasta la Independencia, el concepto del honor se caracteriza por ser la mera expresión de la posición social de una persona y su familia.

Según la autora, las percepciones del honor en Nueva España durante los siglos XVI y XVII, se caracterizaron por una tradición éticocatólica, tal como se había desarollado en la metrópoli, y al contrario de la situación en Europa central y septentrional, sobre todo en los países y regiones protestantes. De este hecho se explica - según Seed - la práctica más tolerante e individual en la jurisdicción de los autos matrimoniales, que intentaba proteger la voluntad de las parejas que deseaban contraer matrimonio en contra de cualquier interés familiar. El concepto del honor, tal como fue defendido por la Iglesia católica como instancia moral y jurídica central en el contexto de los autos matrimoniales, se expresó, por consiguiente, en el precepto del matrimonio por razones de amor, en la estricta exigencia de cumplir las palabras de casamiento y en la defensa del honor sexual de la mujer.

Según la autora, en este concepto del honor y su observancia por la administración de la justicia (eclesiástica) - paradójicamente y, una vez más, al contrario de la situación en la mayoría de las regiones y países europeos-, en el transcurso del siglo XVII al XVIII se operó un cambio debido al influjo del mercantilismo español, del incipiente capitalismo y de la economía de mercado que se fue imponiendo decisivamente en las estructuras y mentalidades sociales en el virreinato de Nueva España. Esta transformación del concepto del honor se expresó en un rechazo cada vez más abierto del matrimonio por razón de amor y en la restricción cada vez más eficiente de la elección individual y libre del cónyuge en favor de un mayor control social llevados a cabo tanto por la política de matrimonio de las familias involucradas como por la presión de la (alta) sociedad y, finalmente, por la legislación de la Corona. En la medida que la «virtud» perdió su trascendencia en la definición del honor personal y familiar, la «posición» fue cobrando importancia social, vinculada a los valores socio-culturales de la ascendencia, de los empleos y cargos, de las relaciones sociales y de la reputación y fama pública. Durante el siglo XVIII la Iglesia cedió cada vez más ante este cambio

R. I., 1997, n. 209 
de mentalidad, para después apoyarlo, hasta llegar a ser eliminada como institución central de control de los matrimonios por la nueva legislación de la monarquía que, a partir del año 1776, aumentó considerablemente el poder de los padres para impedir los «matrimonios desiguales» de sus hijos. Con la famosa Real Pragmática de 1776, extendida a América en 1778, y seguida de varias disposiciones complementarias $^{20}$, el honor se convierte en el concepto e instrumento clave del control y de la estratificación social.

Como ya se ha mencionado, el trasfondo de este desarrollo fue - según Seed- la expansión económica del siglo XVIII. Sin embargo, esa expansión económica no condujo a una amplia movilidad social sino, en primer lugar, al surgimiento de un grupo social de «nuevos ricos», empresarios activos sobre todo en los sectores dinámicos de la minería y del comercio, vinculados además a una parte de la burocracia. Fue justamente este nuevo grupo social el que empleó el concepto del honor como un instrumento para mantener y justificar su posición social destacada, adquirida por el éxito económico. Seed denomina a este grupo social «nueva aristocracia», que, dada su carencia de «conciencia de clase», utiliza todavía conceptos tradicionales de distinción y exclusividad social. Esta fue - según la autora - la característica particular de la sociedad y de la capa social alta de Nueva España en el camino hacia una «sociedad de clases» que sólo se desarolló durante el siglo XIX hasta que, a más tardar en el siglo XX, se ampliaron finalmente las relaciones sociales.

Fuera del virreinato de Nueva España contamos todavía con pocas informaciones sobre el fenómeno del honor y su trascendencia. Contamos, sin embargo, con dos artículos de Frédérique Langue y Pablo Rodríguez ${ }^{21}$. Mientras Rodríguez estudia diferentes autos matrimoniales en Antioquía, Nueva Granada, a partir de la proclamación de la mencionada Real Pragmática de 1776/8, Langue pre-

\footnotetext{
20 Una buena síntesis de la legislación matrimonial presenta Susan Socolow, "Acceptable partners: Marriage choice in colonial Argentina". en: LAVRíN [18], págs. 209213; la obra más importante al respecto es Daisy RíPODAS ARDANAZ, El matrimonio en Indias. Realidad social y regulación jurídica. Buenos Aires, Fundación para la Educación, la Ciencia y la Cultura, 1977.

21 LANGUE, "Les identités fractales: honneur et couleur dans la société vénézuélienne du XVIIIe siècle". Caravelle, Toulouse, vol. 65, 1995, págs. 23-37; RODRIGUEZ, "Elección matrimonial y conflicto interétnico en Antioquía", en idem, Seducción, amancebamiento y abandono en la Colonia. Bogotá, Fundación Simón y Lola Guberek, 1991, págs. 95-124.
} 
senta el caso de una pequeña villa, Carora, en la capitanía general de Venezuela, durante el año 1787, en que tres hermanas se quejaron en el juicio de residencia de un alcalde mayor de que éste se hubiera negado de darles el tratamiento de «Don» contra lo cual ellas declaraban ser de linaje noble y de distinguido honor, refutando a la vez vehementemente ser consideradas como mulatas. Ambos autores destacan la importancia de la idea del honor como un concepto de reputación ligado en su esencia a una calidad y a un grupo étnicosocial (de descendencia blanca o, incluso, mestiza), siendo estas características rasgos evidentes de una continuidad de valores estamentales y, especialmente, aristocráticos europeos en el ámbito de una sociedad colonial.

\section{EL CONCEPTO DEL HONOR EN EL DISTRITO DE LA AUDIENCIA DE QUITO}

El presente estudio se basa en una documentación amplia y diversa. El período objeto de estudio se limita al siglo XVIII hasta la Independencia. He analizado sobre todo los autos matrimoniales tanto de la jurisdicción civil, o sea, del tribunal de la Audiencia (Archivo Nacional del Ecuador, Quito) como de la corte eclesiástica (Archivo de la Curia, Quito). Respecto al tribunal de la Audiencia, encontré 32 casos enjuiciados en los que se mencionaba la desigualdad social y las diferencias de honor como argumentos en contra de un matrimonio. Todos estos casos datan de los años comprendidos entre 1778 y $1818^{22}$. Para este mismo período no he encontrado ningún caso similar en la documentación eclesiástica. Este hecho confirma una vez más la importancia que tuvo la nueva legislación estatal a partir de 1776/8 para los autos matrimoniales. Además, revisé la documentación sobre otros autos pertenecientes a la jurisdición civil y criminal de la Audiencia, como también casos llevados ante el Consejo de Indias (Archivo General de Indias, Sevilla), en los cuales el mantener o defender el honor desempeñaba un papel importante. Otros documentos que permiten obtener informaciones so-

22 La mayor parte de estos casos se refieren a la ciudad de Quito (15), seguida de Guayaquil y Cuenca (5 cada una), después Ibarra (3), Ambato (2), y Loja y Popayán (1 cada una).

R. I., 1997, n. $^{\circ} 209$ 
bre el concepto de honor, tal como se entendía en el distrito de la Audiencia de Quito y como fue también tratado ante la administración de la metrópoli, son las relaciones de méritos, elaboradas por el Consejo de Indias en base a documentos presentados por la parte interesada en una merced del Rey.

Respecto a la composición social de las personas y familias involucradas en los autos matrimoniales o en otros «asuntos de honor» cabe destacar que si bien entre los protagonistas de los casos mencionados se encuentran representantes de las familias más importantes del distrito y de su capital, la ciudad de Quito, una parte considerable pertenecía a sectores sociales más modestos, entre ellos hacendados y mercaderes con un caudal moderado y burócratas de un rango menor que, de todos modos, reclamaban pertenecer a la capa alta de la sociedad.

A fin de caracterizar el concepto del honor vigente en el distrito de la Audiencia de Quito, tal como se desprende de la documentación, a continuación se presentan los términos socio-culturales claves con los que se expresaba el honor (o la honra), o su noción contraria, el «deshonor» o la «vileza», de una persona o familia. Como en los casos ya mencionados de los virreinatos de Nueva España y Nueva Granada, durante el siglo XVIII, la semántica del honor se ubicó en primer lugar en el contexto de un discurso sobre los valores principales de la estratificación o sea de la «jerarquía» social. En este sentido el honor, más que un rasgo o valor personal, era la característica de un grupo social y era entendido como un concepto de distinción y exclusión social.

El honor fue reclamado sobre todo para o por la capa alta de la sociedad, es decir «la nobleza» o «los nobles» (a veces también «la hidalguía» 0 «los hidalgos») y por los que querían pertenecer a este grupo $^{23}$. Otros términos alusivos a la posición social y al honor excepcional de una persona o familia eran: «de la primera distinción», «de distinguida calidad», «vecino» o «familia ilustre», «personas

23 Sobre la nobleza como concepto y grupo social en la Audiencia de Quito véase Christian BüsCHGES, Familie, Ehre und Macht. Konzept und soziale Wirklichkeit des Adels in der Stadt Quito (Ecuador) während der späten Kolonialzeit, 1765-1822. Stuttgart, Steiner, 1996; cf. idem, "Nobleza y estructura estamental entre concepto y realidad social. El caso de la ciudad de Quito y su región (1765-1810), Jahrbuch für Geschichte von Staat, Wirtschaft und Gesellschaft Lateinamerikas. Colonia, Weimar e Viena, vol. 33, 1996, págs. 165-186. 
recomendables» o «caballero principal». A «la nobleza» se oponía la «plebe» o «los plebeyos» que carecían de honor. Otros términos opuestos al concepto del honor eran: «ruin», «vil», «bajo», «ordinario», «de segunda clase», «de humildes principios», «de despreciable calidad», «de baja esfera» u «ordinarísimo».

En el centro de la concepción del honor como distinción social se encuentra sin duda el factor de la ascendencia («ascendientes», «prosapia», «descendencia», «origen», «linaje», «rama», «línea», «cuna», «hijo de ...»). Ser «sujetos [...] esclarecidos en linaje» presuponía principalmente, según la tradición hispánica, la «limpieza de sangre» o sea la descendencia de cristianos viejos. El «deshonor» se fundaba, en cambio, en la «ínfima», «vilísima» o «débil extracción», el «bajo nacimiento», la «ruin prosapia» o la «baja estirpe». Como ya destacó Ann Twinam para todo el área colonial, se consideraban carentes de «honor» un «hijo natural», un «hijo sacrílego», por ejemplo un «hijo de presbítero», o un «hijo adulterio de una india».

La descendencia como una característica del honor de una persona fue, además, una calidad exclusiva de los «españoles» o «blancos», tanto criollos como «chapetones» (españoles nacidos en la metrópoli), todos ellos «limpios de toda mala raza», «limpios de gentes de otras castas» o más concretamente, «libres de la raza de negros, indios y mulatos». Se consideraba vil o deshonrado cualquier «mala mezcla», un «aspecto de zambo indio y chino», o sea, la pertenencia étnica o la descendencia de «indios», «mestizos» (o «montañeses »), «pardos», «mulatos» 0 «zambos».

Junto a la cuestión de una decendencia prestigiosa, el honor o la vileza de una persona o familia se expresaban en el prestigio social de las profesiones y los empleos ejercidos. Así, se hablaba de «empleos de honor», de «empleos honoríficos en lo religioso, político y militar». En cambio se consideraban «oficios viles» o «infames» los «empleos mecánicos», como las actividades del «barbero» o «tejedor», el empleo de «conductor de mulas», de «escribiente en la Real Aduana», de «pulpero» o «cajonero» y, en una ocasión, incluso el empleo de «platero». Igualmente se consideraba de posición social inferior y, por consiguiente, «vil», la situación de dependencia de un «sirviente» o «criado» de otra persona o familia. El lugar más bajo en esta escala profesional de la difamación social se encontraban los esclavos negros y mulatos.

R. I., 1997, n. $^{\circ} 209$ 
Otro aspecto del honor era la apariencia en público de una persona, por ejemplo, la calidad de los atuendos: al «traje de señora» 0 «bien decente» se oponía el «traje de plebeya» o «despreciable». La conducta personal fue también un factor de la noción del honor en el distrito de la Audiencia de Quito. El «proceder honrado» se manifestaba en una «prudente y juiciosa conducta», en «buenas costumbres y conducta» o «buenas operaciones», en un «porte de vida honesta, arreglada siempre a buenas costumbres». De esta manera, las «personas de probidad» debían y solían «dar buen ejemplo al público». La vileza, en cambio, se expresaba con una «indigna», «reprobada conducta», por ejemplo en un «dilatado concubinato», evidencia del «invilecimiento y bajesa de ánimo».

Todos los mencionados rasgos del honor, es decir la «dimensión objetiva» o «material» de este concepto, se imponían como valores sociales, de una manera más bien informal, a través de la fama pública, o sea la reputación ${ }^{24}$. Esta dimensión central del concepto del honor se manifiesta en la documentación estudiada en la gran cantidad de expresiones como «conceptuado», «conocido», «tenido» o «reputado por...» (tal posición, calidad). La particular reputación de las «personas honradas» se expresaba en su derecho o su reclamación de ser tratados con el distintivo de «Don», de gozar de «estimaciones y aprecios» en «actos privados y públicos». Esta reputación se refería sobre todo a «los honores que gozan los nobles». La «plebe», en cambio, se consideraba «despreciable», caracterizada de «desdoro», siempre en el centro de la «infamia pública».

Finalmente, en la documentación estudiada también se encuentran elementos conceptuales de un particular honor femenino, primordialmente sexual, en el sentido que ha sido indicado por Twinam. Cabe destacar, sin embargo, que el honor femenino, como en el caso del virreinato novohispano investigado por Seed, desempeñó solamente un papel marginal en los juicios matrimoniales, tanto en términos de cuantidad como de calidad ${ }^{25}$.

\footnotetext{
${ }^{24}$ Cf. la trascendencia social de la "voz común" y los ejemplos discutidos en Tamar HERZOG, La administración como un fenómeno social: La justicia penal de la ciudad de Quito (1650-1750). Madrid, Centro de Estudios Constitucionales, 1995, págs. 253-278.

25 Véase i.e. ANE/Q, Matrimoniales, caja 3, expediente 3-VI-1785, fol. 131v-132; ibidem, expediente 6-VIII-1787, fol. 67v. El respeto del honor (femenino) fue reclamado, incluso, en un caso por un mulata guayaquileña que a finales del siglo XVIII trataba de defender su libertad contra su antiguo amo que la siguió considerando como su esclava, y
} 
Una recopilación y evaluación sistemática de las diferentes connotaciones del concepto del honor, tal como se desarolló en el distrito de la Audiencia de Quito, evidencia un claro predominio de los factores de descendencia y de los empleos distinguidos. Ambos requisitos eran entendidos como una unidad evidente y necesaria, vinculada en su más alta expresión y en su esencia propia a la nobleza como posición y capa social más elevada. De esta manera, el honor de una persona se deducía y se le concedía en primer lugar por su pertenencia a un grupo social, sobre todo a la nobleza. Al igual que la nobleza, también se consideró el honor como una característica transmisible hereditariamente $\mathrm{y}$, por consiguiente, propia de toda una familia, de un linaje.

En cambio, el honor entendido como virtud tuvo una trascendencia social menor, más bien limitado a la esfera privada. Por otro lado, en su dimensión social, también se consideraba la virtud como un rasgo típico del honor de un linaje o de un grupo social, es decir, un elemento del modo de vivir que reclamaba para sí un determinado grupo y que también se esperaba de él. En una relación de méritos del año 1764 sobre el comerciante quiteño Pedro Buendía Dávila que reclamaba para sí la posición social de noble, se destaca «que correspondiendo [...] al honor de sus ascendientes, sirvió de cadete en el regimiento de infantería de Murcia [...] con la aplicación y conducta correspondiente a su nacimiento» ${ }^{26}$. De manera similar, en el mismo año la Audiencia de Quito escribió en un informe sobre Manuel Guerrero y Ponce de León, heredero del Condado de Selva Florida, que éste «ha imitado a sus gloriosos progenitores adelantando con el mérito, y conservando con sus arreglados procederes la nobleza y el honor que de ellos heredó» ${ }^{27}$.

La totalidad de lo expuesto sobre un concepto de honor estamental, basado en la evaluación social de la descendencia y de los empleos y que se asignaba en su más alta expresión a la nobleza, se confirma en el siguiente ejemplo que, a pesar de su extensión, me

\footnotetext{
por esta calidad, careciente de cualquier honor, María EUGENIA CHAVES, "Las estrategias retóricas de la libertad: el amo y el esclavo en Guayaquil del siglo XVIII", ponencia leída en el XI Congreso Internacional de la Asociación de Historiadores Latinoamericanistas Europeos, Liverpool, 17-22 de septiembre de 1996.

26 AGI, Quito, legajo 231.

27 AGI, Quito, legajo 224.
} 
permito citar. Se trata de una recapitulación de los argumentos presentados en los años ochenta del siglo XVIII por un procurador del vecino lojano Manuel Valdivieso para justificar la negativa de éste a aceptar el matrimonio entre su hija Baltasara y Teodoro Jaramillo y evitar así el «deshonor» que este enlaze significaría para toda su familia:

«A pesar de la astusia y cabilación con que ha procurado el referido Teodoro sin otro mérito que los bienes de su fortuna exaltarse a una jerarquía muy superior a la de su baja estirpe, no deja ser hijo de Juan Jaramillo, habido y procreado de otro Don Juan Jaramillo y de Doña Margarita González, Valdivieso y Montesdoca, quien por el mismo caso de no saber certidumbre de su padre, debe seguir la naturaleza de india que tuvo su madre; y de María de Ureña [...], mujer del truquero Bartolomé Gálvez, gente toda ruin, que como tal se han empleado en los ministerios serviles y mecánicos proporcionados a su calidad, ejerciendo por esto Jaramillo el oficio de platero bajo la sombra de su tío Esteban Ureña, que se lo enseñó como oficial público, hasta que pasó a servir de mayordomo la fábrica de casa a Don Miguel Carrión, y luego de arriero o conductor de sus mulas, en cuyo ejercicio continuó con Don Pedro Javier Valdivieso muchos años, sin desdeñar de todos aquellos ministerios con que hizo fortuna, y compró la Hazienda del Catamayo que le ha aumentado el caudal, y ensoberbecido de modo que, olvidado tan humildes principios, solicita no sólo igualar pero aún exceder la distinguida calidad de mi parte, y toda su familia, confabulado con los testigos de igual extracción a la suya, que [...] se han empeñado en ennoblecer su ruin prosapia, no sólo por el Don con que prodigamente la honran, sino también por la nobleza misma atribuida a sus ascendientes, quienes por su despreciable calidad jamás ejercieron cargo alguno honorífico de aquellos en que se emplean los sugetos de distinción; y siempre abatidas a lo más mecánico, no han pasado de plateros o sirvientes. El mismo Jaramillo, con todo caudal que tiene, apenas blasona el timbre de mayordomo de la ciudad; siendo un cargo que jamás lo han obtenido los vecinos ilustres de la principal nobleza.»28.

Resulta sumamente interesante que el procurador rechaza especialmente la calidad de (si bien modesto) «nuevo rico» de la parte opuesta, es decir la base - según el procurador-meramente económica de su pretensión social (incluída en ésta la solicitud de matrimonio), base perteneciente a una identidad social más bien mo-

$28 \mathrm{ANE} / \mathrm{Q}$, Matrimoniales, caja 3, expediente 3-VI-1785, fol. 117-117v. 
derna a la cual el procurador contrapone todos los prejuicios sociales correspondientes al régimen estamental (nobleza, ascendencia, honor).

Dado que el honor de un individuo estaba, en el fondo, ligado directamente a su pertenencia a un grupo social, una ofensa al honor significaba una agresión directa contra la posición social de una persona. Con el «deshonor» amenazaba la pérdida de la posición social y la «cualificación» para desempeñar funciones importantes en la sociedad. Por tal motivo, las personas y familias involucradas mostraron a veces una gran persistencia e invertieron, en algunos casos, una cantidad considerable de tiempo y dinero, al acudir al tribunal de la Audiencia o incluso al Consejo de Indias para defender su honor o para que les fuera restituido.

Los autos matrimoniales forman parte de estos esfuerzos de mantener y defender el honor de una familia. Además de estos casos ya suficientemente conocidos también en otras regiones de la América Española, cabe destacar otro caso parecido pero perteneciente a otro contexto. En 1793, en el transcuro de una querella por la propiedad de una cantidad de tejidos, se produjo un enfrentamiento verbal entre dos comerciantes quiteños, Pedro Montúfar y Simón Sáenz de Vergara. Poco tiempo después, Montúfar acusó a Sáenz ante el tribunal de la Audiencia de «agravios e injurias propagadas contra el honor» de su persona y de sus padres, los Marqueses de Selva Alegre. Para justificar la acusación, el procurador de Montúfar alegó que entre la familia de su cliente y la de Sáenz existía una gran diferencia social. Destacó sobre todo el hecho de que tanto Pedro Montúfar como su padre, primer marqués de Selva Alegre y antiguo presidente de la Audienca de Quito, habían ejercido empleos importantes y que también los ascendientes de su madre, Rosa de Larrea, «vinieron destinados a la América a ocupaciones dignas de su cuna», mientras que Sáenz, por el contrario, había llegado a la ciudad de Quito como simple «cajero» de otro comerciante y que por ende «no es una persona igual, no sólo por el ministerio público, sino también por razón de nobleza», por lo que las ofensas pronunciadas por éste en público debían ser severamente castigadas. Así, el procurador exigió el destierro perpetuo de Sáenz de la ciudad.

La gravedad que la familia de los Montúfar atribuyó a lo sucedido se ve claramente en el hecho de que, cuando la Audiencia denegó la demanda (puesto que la querella originaria, en este momento, era ya resuelta), Pedro Montúfar y su hermano Juan Pío, segundo mar-

R. I., 1997, n. $^{\circ} 209$ 
qués de Selva Alegre, acudieron directamente al Consejo de Indias para conseguir la deseada pena ejemplar para Sáenz y obtener de este modo la debida «satisfacción» para su familia ${ }^{29}$.

La dimensión social, o sea estamental, fue, por consiguiente, la característica primordial del concepto del honor en el distrito de la Audiencia de Quito y como tal fue sostenido en la mayoría de los casos, especialmente en los autos matrimoniales, para comprobar y justificar la elevada posición social de una persona y su familia. Cabe señalar que en la afirmación del honor y la elevada posición social no sólo intervinieron personas y familias de la misma capa social que se apoyaban mutuamente. En las disputas sobre el honor de las personas y familias involucradas en los autos matrimoniales, la parte «acusada» de pertenecer a un grupo social más bajo no solía poner en duda la posición social alta de la parte opuesta y, en cambio, trataba de probar con los mismos argumentos poseer la misma calidad social y el mismo honor, afianzando de este modo la estructura y la mentalidad social vigentes.

Sin embargo, la documentación revisada contiene también algunos casos que, a pesar de su calidad de excepciones obvias, nos recuerdan la dimensión funcional o incluso instrumental del concepto del honor. Eso quiere decir que tanto este concepto como los elementos de la distinción y estratificación social vinculados a éste no deben entenderse como una expresión directa de una estructura superpuesta en la que los individuos particulares se movían como marionetas. Nos encontramos frente argumentaciones y actuaciones de «actores sociales». Si bien estos actores estaban influenciados o incluso condicionados por una estructura y mentalidad social preexistente, sus actuaciones sociales fueron al mismo tiempo el resultado de una interpretación, o sea, de una apropiación individual y, de este modo, a veces de una divergencia de opiniones que se expresaba en la modificación o el rechazo de la estructura y mentalidad predominantes o incluso, a largo plazo, en el cambio de éstas ${ }^{30}$. Por eso, en

29 ANE/Q, Criminales, caja 149, expediente 2-X-1793; AGI, Quito, leg. 220; la documentación no contiene informaciones sobre el juicio final del caso.

30 Como destaca Burke, las identidades e imágenes sociales, y los términos en que éstas se expresan, no se puede considerarlas como meros reflejos de la realidad social puesto que "language creates the social reality it purports to describe", Burke, "The language of orders in early modern Europe", en M.L. Bush (de.) Social Orders and Classes in Europe since 1500: studies in Social Stratification Londres y Nueva York 1992, pág. 8. 
las críticas del concepto de honor social en el distrito de la Audiencia de Quito se pueden distinguir dos tipos: uno de carácter tradicional, que no era sino una variación de la estructura vigente y, por consiguiente, significaba en el fondo su confirmación; y otro tipo, de carácter más bien «moderno» que debe entenderse, y se entendía a si mismo, como una clara oposición a esta estructura predominante.

Como una crítica inherente al discurso tradicional sobre el contenido social del concepto del honor se presenta la argumentación del apoderado del mencionado vecino de Loja, Teodoro Jaramillo, con la cual trató de demostrar que el rango social, o sea, la nobleza y el honor de su cliente, no difería de la del cónyuge elegido, Baltasara Valdivieso. En la tradición del discurso de la época moderna sobre la «nobleza de virtud», en contra de la idea de la nobleza basada exclusivamente en la sangre, o sea la ascendencia, el apoderado de Jaramillo expuso la posición social de su cliente como sigue:

\footnotetext{
«Todo lo que se hace más recomendable en vista de [...] sus buenas costumbres y conducta; pues aunque el procurador contrario califica de osiosa y superflúa esta justificación en el proceso, mi parte estimó producirla como más interesante al honor de su persona, porque [...] la nobleza política que consiste en las buenas costumbres es mejor que la legal y civil de sangre, cuanto excede la virtud moral a la natural, y la nobleza de acciones heróicas a la de la sangre generosa» ${ }^{31}$.
}

También la argumentación del abogado quiteño Dr. Bernardo de León y Carcelén fue de carácter tradicional, cuando en el año 1805 rechazó el intento de su hermano Tomás y otro pariente, el quinto marqués de Villa Rocha, Felipe Carcelén, de impedir su matrimonio con una mulata, ambos mayores de edad. El marqués había objetado que tal enlaze violaba «el sentimiento de honor de todas estas familias [de la nobleza quiteña], y aún de todo el público, que nos ha mirado siempre con la distinción y aprecio que corresponde a la nobleza de nuestra cuna». León, en cambio, remitió a la tradición cristiana cuando destacó que para dos personas que se aman no existe ninguna «desigualdad», lo que ya había sido así en el caso de Adán y Eva, pues en el Evangelio no se hablaba de «esta igualdad fantástica

31 ANE/Q, Matrimoniales, caja 3, expediente 3-VI-1785, fol. 130.

R. I., $1997, \mathrm{n}^{\circ} 209$ 
y quimérica», lo que demostraba que su decisión de contraer matrimonio estaba de acuerdo con la fe y la conducta cristianas ${ }^{32}$.

Otro argumento tradicional en contra de una concepción rígida de un honor social que trataba de restringir esta distinción social a la capa más alta, o sea la nobleza, fue el intento de revalorizar la artesanía, es decir, las «artes liberales», haciéndolas compatibles con el honor, o incluso como uno de sus orígenes y fundamentos, al contrario de otros «oficios manuales» todavía considerados como «viles» ${ }^{33}$.

La única crítica fundamental del concepto del honor, basado en la reputación emanada de la descendencia y del ejercicio de empleos prestigiosos y perteneciente en primer lugar a la nobleza, fue la argumentación de Antonio Sánchez Maldonado, vecino de Quito, cuando rechazó las reservas de María Yépez contra el matrimonio de su hijo Ramón Ruiz con Rosa Sánchez Maldonado. Antonio Maldonado condenó abiertamente la concepción del honor y de la posición social como una calidad propia de un linaje o de un grupo social. Destacó en cambió la importancia y superioridad del rendimiento individual para la evaluación social de una persona. Ya el tono, rigoroso y consciente de si mismo, en que Maldonado se expresó sobre las calidades de sus hijas y ascendencia muestra el carácter subversivo, si no revolucionario de su punto de vista:

\footnotetext{
«Alzen las manos al cielo esas muchachas: sepan que tienen maridos honrados de bien, trabajadores, y que no son de esos petimetres mal entretenidos que a la sombra ridícula de sus Dones verdaderos o supuestos graban a la sociedad en vez de darla algún alivio. Si yo tuviese muchas hijas, más bien las daría a un zapatero honrado que a estos vagamundos enoropelados. Otros pecados tendrá Dios que pedirme cuenta; pero el de la vanidad, el de la loca soberbia, el de el orgullo ridículo de distinguirme y pretender que me veneren, porque mis padres fueron nobles de solar conocido y de ilustre hidalguía, según me parece, no son culpas que hayan contaminado mi espíritu. Estoy persuadido de que estas ideas sólo pueden hacer la vanagloria de esa mísera caterva de entendimientos plebeyos, bastardos y mesquinos que no saben distinguir que la única grandeza del hombre es la que procede del alma, y que en la
}

32 ANE/Q, Matrimoniales, caja 7, expediente 7-IX-1805.

33 ANE/Q, Matrimoniales, caja 3, exp. 6-VIII-1787; cf. las Reales Cédulas de Carlos II y Carlos III sobre la compatibilidad de "industria" y nobleza. 
realidad ninguno es de mejor sangre que otro, y que un perro sano tiene mejor sangre que un hombre enfermo» ${ }^{34}$.

\section{CONCLUSIONES}

A la cuestión planteada al principio de esta ponencia acerca de la trascendencia y función social de «las leyes del honor» he intentado responder mostrando la base primordialmente social o, mejor dicho, estamental que tuvo el concepto del honor en el distrito de la Audiencia de Quito. Al lado de rasgos más bien individuales y de componentes de virtud y a pesar de algunas críticas de la mentalidad predominante, el concepto del honor era la expresión de la distinción y exclusivad social, o sea de la reclamación de tal posición social, perteneciente en su esencia a un grupo social y, ante todo, a los nobles o a personas que reclamaban tal status. De esta manera, el concepto del honor sirvió como instrumento para regular las relaciones y la estratificación social y como justificación de la jerarquía social en cuya cima se encontraba situada la nobleza como estamento de honor propio. En la práctica social, durante el siglo XVIII, el honor significó sobre todo reputación o fama, vinculada en su esencia, como una calidad transmisible por herencia, a una familia, o sea, a un linaje.

Así, en el distrito de la Audiencia de Quito, durante el siglo XVIII, el concepto del honor constituyó el centro y la esencia de una pronunciada mentalidad estamental. Esta estructura y mentalidad social es bien conocida en las sociedades europeas del Antiguo Régimen. Tal como se ha expuesto en la introducción al tema, en las sociedades tradicionales, caracterizadas por el tipo ideal (Idealtyp) de «sociedad estamental» o «de estamentos», la posición social de los individuos deriva de la evaluación del grupo o estamento al que éstos pertenecen, estructura fortalecida por convenciones y leyes particulares que tenían la función de impedir o limitar en lo posible la regulación de las relaciones sociales por el mercado (o los mercados) según los factores de la capacidad de rendimiento y de la propiedad. Como sociedad colonial pluriétnica, la mentalidad estamental, tal como se había desarollado en la Audiencia de Quito en el siglo XVIII, muestra, además, una fuerte dimensión étnica.

34 ANE/Q, Matrimoniales, caja 5, expediente 18-VIII-1794, fol. 33v-34v. 
Comparando el enfoque teórico y los resultados de mi investigación (y de la de Langue y Rodríguez) con el estudio de Patricia Seed sobre la trascendencia y la función del honor en el virreinato de Nueva España deben destacarse algunas diferencias obvias. Estas diferencias se refieren en su esencia a la tesis de Seed sobre la reinterpretación y, como una consecuencia de ésta, la instrumentalización del concepto del honor, entendido originariamente como un valor exclusivamente individual y ético-cristiano, y después, a partir de principios del siglo XVIII, interpretado y utilizado como un elemento de la diferenciación y exclusividad social, consecuencia según la autora- de la transformación capitalista de la sociedad novohispana durante el auge económico del siglo XVIII.

Quisiera presentar algunas reflexiones sobre estas diferencias, que por una parte giran en torno a una crítica general del planteamiento y de la metodología de Seed y por otra parte, ponen de relieve algunos elementos de una diferenciación regional respecto a la trascendencia del concepto del honor en el espacio colonial.

En principio hay que refutar la tesis de Seed sobre el predominio de la idea de virtud y de la dimensión ético-católica del concepto del honor en el virreinato de Nueva España durante los siglos XVI y XVII $y$, sobre todo, de su supuesta tradición española, que la autora considera como un indicio de una estructura relativamente abierta e igualitaria de la sociedad española y novohispana en aquella época. Basta echar un vistazo a los estudios ya mencionados de Caro Baroja, Chauchadis y Maravall para desvirtuar la visión un poco «romántica» de la realidad y mentalidad social de España durante los primeros dos siglos de la época moderna ${ }^{35}$. La idea del «virtud» fue, también en la península, durante los siglos XVI y XVII, solamente un rasgo del complejo concepto del honor que en su función social predominante se encontraba ligado, de todas maneras, a las estructuras estamentales de la sociedad. De este modo, la dimensión social y estratificadora del concepto del honor se encuentra expresada ya en los códigos jurídicos medievales de las Siete Partidas y de las Leyes de Toro.

\footnotetext{
35 CARO BAROJA, "Religion, world views, social classes, and honor during the sixteenth and seventeenth centuries in Spain", en: PeristianY y PITT-RIVERS, Honor and grace [3], págs. 91-102; CARO BAROJA, "Honor y vergüenza", en: PeristianY [3]; ChaUChadis y MARAVALL [11].
}

R. I., $1997, \mathrm{n}^{\circ} 209$ 
Para el caso novohispano hay que remitir, por otra parta, a los estudios que muestran claramente la estratificación social durante el siglo $\mathrm{XVII}^{36}$. Además, Seed misma menciona algunos autos matrimoniales enjuiciados por los jueces eclesiásticos en que, ya durante los siglos XVI y XVII, algunas parejas deseosas de contraer matrimonio se quejaban de la oposición ejercida por sus padres ${ }^{37}$. Según las quejas de estas parejas, los motivos alegados por sus padres se basaban -según la autora- en un mero interés personal o familiar, fundado en motivos económicos o sociales ${ }^{38}$. Del hecho que estas intervenciones familiares ante el juez eclesiástico sean más bien excepciones no se puede desprender, sin embargo, la evidencia de una estructura y mentalidad más abierta de la sociedad novohispana durante estos siglos, sino que muestra solamente las normas eclesiásticas empleadas para dictaminar sobre los motivos de los contrayentes. Estas normas, sobre todo las resoluciones del concilio de Trento, insistían en principio en la libre elección del cónyuge, basada únicamente en el afecto mutuo de la pareja respectiva, y rechazaban, al mismo tiempo, cualquier intervención por parte de los padres o de otras personas por intereses propios. Así pues, no es sorprendente que en los documentos del juzgado eclesiástico no figuren muchos casos de intervenciones familiares y, que en ellos sólo se obtengan pocas informaciones sobre su probable trasfondo social o económico, puesto que ante esta institución y según las normas empleadas por ésta, estas intervenciones por lo general no tenían ninguna perspectiva de ser atendidas favorablemente. Por eso, la mayoría de las informaciones sobre estas intervenciones provienen de las quejas de los contrayentes.

Teniendo en cuenta nuestros conocimientos sobre la estratificación social de la sociedad novohispana durante el siglo XVII, a mi modo de ver, la marcada ausencia de oposiciones familiares abiertas por razones sociales y económicas en la documentación de autos matrimoniales ante el juzgado eclesiástico debe interpretarse como

36 Véase i.e. J.I. ISRAEL, Race, class and politics in colonial Mexico 1610-1670. Oxford, Oxford University Press, 1975; José F. DE LA PEÑA, Oligarquía y propiedad en Nueva España (1550-1624). México, Fondo de Cultura Económica, 1983; cf. R. Douglas COPE, The limits of racial domination. Plebeian society in colonial Mexico City, 1660-1720. Madison, The University of Wisconsin Press, 1994.

37 Seed [19], págs. 42-46 y pág. 31 (nota 43).

38 Ibidem, págs. 53-60. 
un reflejo de los dogmas y de la política de la Iglesia católica, los cuales ésta, como institución decisiva para enjuiciar estos casos, logró imponer sobre los patrones socio-culturales mucho más complejos y rígidos.

Esta situación cambió totalmente con la política de la corona española, cuando ésta eliminó la influencia de la Iglesia en los conflictos matrimoniales con la publicación de la pragmática sanción del año 1776 y las cédulas y provisiones posteriores, con las cuales se adaptó la nueva legislación matrimonial a la realidad social del espacio colonial. Esta nueva «legislación social» de la época colonial tardía, controlada por autoridades seculares (alcaldes ordinarios, corregidores, gobernadores y, en segunda instancia, por el tribunal de la Audiencia), debe entenderse, no sólo como la expresión de una nueva política de la corona, sino también como un reflejo de los valores socio-culturales de la sociedad, ante los cuales la Iglesia, o sea el juzgado eclesiástico, aparentemente ya había empezado a ceder antes ${ }^{39}$. De todos modos, cabe recalcar que los fundamentos de la estratificación social y el carácter complejo y la trascendencia del concepto del honor no pueden analizarse solamente sobre la base de los autos matrimoniales enjuiciados ante los jueces eclesiásticos ${ }^{40}$.

Finalmente, queda por exponer el origen, las características y el desarrollo de los valores socio-culturales, y de su trasfondo económico, en el distrito de la Audiencia de Quito, puesto que se diferencia marcadamente del caso novohispano, tal como lo presenta Seed. El distrito de la Audiencia de Quito, sobre todo la sierra norte y central, tuvo su época económica más dinámica durante el siglo XVII, cuando la industria textil, basándose en las grandes manufacturas de la sierra, fue el eje de la economía de todo el distrito. En cambio el siglo XVIII estuvo marcado por una crisis económica, originada por el descenso de la producción manufacturera debido al aumento de la competencia ejercida por los textiles europeos (y de la industria doméstica indígena) en el espacio colonial ${ }^{41}$. Por otra parte, es justa-

39 Ibidem, págs. 177-189.

40 Lo mismo se debe decir respecto a las reflexiones, también mencionadas por Seed, tanto sobre el principio del matrimonio por razones de afecto personal como sobre el honor entendido en primer lugar como una virtud, tal como se encuentran en la literatura jurídica, teológica y moralística de los siglos XVI y XVII, puesto el problema metodológico de comprobar su relevancia en la realidad social.

${ }^{41} \mathrm{El}$ auge económico de la costa se desarolló sobre todo en el siglo XIX. 
mente en el siglo XVIII, cuando, al igual que en el caso novohispano, nos encontramos frente al fenómeno de una marcada estratificación social y de valores socio-culturales en los que predominaba el interés de distinción y exclusividad social, tal como se manifestó en el concepto del honor y del predominio social de la nobleza anteriormente mencionados.

De este modo, el distrito de la Audiencia de Quito y sobre todo la sierra norte y sur, donde el concepto del honor estamental fue probablemente observado y empleado de una manera más estricta, no resultó afectado - a no ser de un modo desfavorable - por la expansión del capitalismo, de la economía de mercado y de una integración en la economía mundial, sino que más bien se caracterizó por el estancamiento y la autarquía. Por consiguiente, los valores socio-culturales no fueron influenciados durante el siglo XVIII por nuevas fuerzas o tendencias (económicas) y estos valores tampoco fueron defendidos por nuevos sectores sociales. A mi modo de ver, la estructura y la mentalidad social en el distrito de la Audiencia de Quito fueron el resultado de un continuo desarrollo de diferentes elementos y conceptos de la estratificación social durante la época colonial, los cuales se parecían, en su esencia y función, a los de las sociedades europeas del Antiguo Régimen, sobre todo a partir del siglo $\mathrm{XVII}^{42}$.

Cabe preguntarse en qué medida se diferenciaron verdaderamente el desarrollo y las características de los valores socio-culturales entre el distrito de la Audiencia de Quito y del virreinato de Nueva España. Además del problema de la restringida base documental del estudio de Seed, tampoco convence el intento de la autora de replegar los conceptos tradicionales de la distinción social, como por ejemplo el prestigio de los cargos militares y eclesiásticos, a la Edad Media cuando por otra parte sostiene la tesis de que los cambios económicos del siglo XVIII fueron los que engendraron estos valores «tradicionales» de la posición social.

Parece más probable, por consiguiente, que estos valores tradicionales de distinción y exclusividad social, y su manifestación en el concepto del honor, hubiesen experimentado un continuo desarrollo durante la época colonial, también en el virreinato de Nueva España.

42 Véase para la sierra norte y central del distrito de la Audiencia de Quito la introducción y el capítulo A en BüsCHGES, Familie, Ehre und Macht [22].

R. I., 1997, n. $^{\circ} 209$ 
La discrepancia entre el mantenimiento de valores sociales tradicionales y la creciente importancia de las actividades empresariales para la movilidad social, durante el siglo XVIII, no son, en cambio, ningún caso excepcional en la historia de las sociedades del Antiguo Régimen, sobre todo en lo que se refiere al papel socio-económico de la nobleza, puesto que la simultaneidad de continuidades y discontinuidades es una característica típica del proceso de la transformación social de los siglos XVIII y XIX hacia la «sociedad moderna».

En el caso de España y de su imperio colonial hay que tener en cuenta, además, la política social y económica contradictoria de la corona española, especialmente respecto al papel de la nobleza. Esta política puede caracterizarse como el intento de una «modernización defensiva», empleada desde una posición de «retraso» (económico y social) de la península, respecto a las regiones más dinámicas del norte y oeste de Europa. Esta «modernización defensiva» se caracterizó por el intento de reformar las estructuras económicas e incentivar las actividades empresariales, manteniendo al mismo tiempo el orden social tradicional y defendiendo la destacada posición y función social de la nobleza. La nueva legislación matrimonial evidencia muy bien los rasgos contradictorios de esta «modernización defensiva». Además, la corona mantuvo los mecanismos tradicionales de la recompensa social, o sea, de las mercedes, para promover las actividades económicas, como por ejemplo la concesión de títulos nobiliarios a empresarios existosos, hecho que, al final, tuvo más bien el efecto de mantener y reforzar la mentalidad social tradicional ${ }^{43}$.

Finalizo con la observación de que debe profundizarse la investigación sobre la relación entre el desarrollo económico y la mentalidad social y sobre las diferencias regionales en el espacio colonial español. Además, sería especialmente interesante investigar si la noción del honor tuvo la misma importancia para la creación de las identidades de los estratos sociales inferiores y de qué manera la idea del honor de éstas difería de la de las capas sociales altas.

43 Cf. i.e. Frédérique LANGUE, Mines, terres et société à Zacatecas (Méxique) de la fin du XVII ${ }^{e}$ siècle à l'ìndependence. Paris, Publications de la Sorbonne, 1992.

R. I., 1997, n. ${ }^{\circ} 209$ 
The present article studies the nature and function of the concept of «honour» in the district of the audiencia of Quito during the 18th century. It analizes a broad selection of documents, for the most part of judicial origin. Honour is presented basically as a concept of social distinction and exclusion, employed by the higher strata of the different local societies. The honour discourse reflects social identities which go beyond purely economic features and shows in this way caracteristics which are typical for societies of the Old Regime.

R. I., 1997, n. 209 